\title{
Sea anemones and brittle stars: unexpected predatory interactions during induced in situ oxygen crises
}

\author{
B. Riedel $\cdot$ M. Stachowitsch $\cdot$ M. Zuschin
}

Received: 7 February 2007 / Accepted: 4 December 2007 / Published online: 10 January 2008

(C) The Author(s) 2007

\begin{abstract}
During oxygen crises, benthic faunas exhibit a series of behavioural patterns that reflect the duration and severity of the event. During artificially induced oxygen deficiencies at $24 \mathrm{~m}$ depth in the Northern Adriatic Sea, we photographically documented predation by the sea anemones Cereus pedunculatus (Pennant, 1777) and Calliactis parasitica (Couch, 1842) on the brittle star Ophiothrix quinquemaculata (DelleChiaje, 1828). Five predatory events were recorded with four anemones during nine deployments totalling $817 \mathrm{~h}$ of observation. Under near-anoxic conditions, individuals of both actinians made contact with, pulled in and consumed the brittle stars. The duration of each predatory event was 1.5-7.5 h. In three of the five events, brittle star remains were regurgitated after an additional $2.0-12.5 \mathrm{~h}$ of digestion by the anemones. Our time-lapse sequences demonstrate that oxygen deficiency, beyond eliciting a series of specific behaviours in members of each species, also promotes previously unobserved interspecific interactions. Our results show that sea anemones are not only highly resistant to anoxia, but may also benefit by taking advantage of prey that are more vulnerable to anoxic conditions.
\end{abstract}

Communicated by M. Wahl.

B. Riedel $(\bowtie) \cdot$ M. Stachowitsch

Department of Marine Biology, University of Vienna,

Althanstrasse 14, 1090 Vienna, Austria

e-mail: bettina.riedel@univie.ac.at

M. Zuschin

Department of Paleontology, University of Vienna,

Althanstrasse 14, 1090 Vienna, Austria

\section{Introduction}

The level of dissolved oxygen is a crucial environmental variable that has changed drastically in shallow coastal marine ecosystems worldwide (Diaz and Rosenberg 1995). "Dead zones", caused by hypoxia (oxygen concentrations $<2.0 \mathrm{ml} \mathrm{l}^{-1}$ ) and anoxia (no oxygen) in bottom-water layers, top the list of emerging environmental challenges (UNEP 2004), and the problem is likely to become worse in the coming years ( $\mathrm{Wu} 2002$ ).

The point at which benthic animals are affected by low oxygen concentrations varies, but first indications of stress generally begin to appear when oxygen drops below 2.0-3.0 mg 1 $1^{-1}$ (1.4-2.1 $\mathrm{ml} \mathrm{l}^{-1}$; Rabalais and Turner 2001). Direct effects of exposure to hypoxia such as migration, physical inactivity and mass mortalities are well documented (Stachowitsch 1984; Buzzelli et al. 2002; Montagna and Ritter 2006). Reproduction and growth may also be affected (Breitburg 1992; Miller et al. 2002; Stierhoff et al. 2006). Beyond these direct effects, there is increasing evidence for indirect effects (Eby et al. 2005) such as changes in competition and predation (Brante and Hughes 2001; Sagasti et al. 2001; Decker et al. 2004). Although mobile benthos are able to migrate out of the affected area, the less mobile fauna-unable to escape or avoid hypoxic watersexhibit a series of behavioural patterns in response to decreasing oxygen concentrations (Mistri 2004). Infauna, for example, emerge from the sediment surface. Epifaunal organisms attempt to raise themselves above the hypoxic bottom layer, either by moving onto higher substrates (Stachowitsch 1991) or raising their bodies (i.e. arm-tipping brittle stars, siphon-stretching bivalves or tiptoeing crustaceans; reviewed by Diaz and Rosenberg 1995). These hypoxia-induced behaviours, however, may render the animals more vulnerable to predation ( $\mathrm{Wu} 2002)$. They may 
also alter predator-prey interactions, whereby predation rates increase or decrease (e.g. the flounder Platichthys flesus: Tallqvist et al. 1999) depending on the relative tolerances of predator and prey to anoxia (Breitburg et al. 1994). Some marine predators even switch their prey items to optimally exploit the prey most sensitive to low oxygen concentrations (Sandberg 1994). For example, with decreasing oxygen concentrations the diet of demersal fish in the York River, Chesapeake Bay (Virginia) shifts from crustaceans to deep-burrowing infaunal organisms lying moribund on the sediment surface (Pihl et al. 1992).

The Northern Adriatic, a shallow (mean depth $35 \mathrm{~m}$ ), semi-enclosed sea, has a long history of seasonal hypoxia and anoxia due to water column stratification (Justic 1987). Anthropogenically induced long-term eutrophication (Marchetti et al. 1989; Barmawidjaja et al. 1995) has increased the frequency, duration and severity of oxygen stress during recent decades (Danovaro 2003; Lotze et al. 2006). Today, the Northern Adriatic is a case study for eutrophication with the full range of typical symptoms such as oxygen depletion, altered behaviour and mortality of benthic organisms, as well as marine snow events. Macroepifauna communities are widely distributed in the Gulf of Trieste (Fedra 1978; Zuschin et al. 1999). The community on the fine-sediment substrates at $\sim 24 \mathrm{~m}$ depth largely consists of interspecific aggregations termed multi-species clumps (Fedra et al. 1976) or bioherms. The brittle star Ophiothrix quinquemaculata is one of the three designating species in this benthic community (Ophiothrix-RenieraMicrocosmus community) and is found almost exclusively on sponges and ascidians, with its arms extending upward in a suspension-feeding position. The sea anemones Cereus pedunculatus and Calliactis parasitica also are prominent members of this community. Cereus pedunculatus lives partially buried in the sediment with the tentacle crown on the sediment surface, although some are "integrated" into epifaunal aggregations. Calliactis parasitica shows a different life habit as a common mutualistic symbiont on gastropod shells occupied by hermit crabs, and as an epibiont on living gastropods (Stachowitsch 1980; Caruso et al. 2003). Little information is available on the prey composition of these two particularly abundant anemone species in the Mediterranean. Chintiroglou and Koukouras (1991, 1992), who studied the diet of both anemones, showed that Calliactis parasitica is a non-selective omnivorous suspension feeder, but also can remove food particles from the sediment through tactile tentacle motion. It preys upon a wide spectrum of organisms, particularly gastropods and crustaceans (Chintiroglou and Koukouras 1991). Cereus pedunculatus is an opportunistic omnivorous suspension feeder; due to its relatively short tentacles; this anemone cannot actively search for prey. It feeds almost exclusively on organic detritus and on motile prey that blunder into its tentacles. Cereus also feeds almost exclusively on crustaceans, mainly amphipods and decapods (Chiniroglou and Koukouras 1992); echinoderms have never been identified as prey items. Conversely, studies on predators of ophiuroids in shallow-water habitats have focused on demersal fish (Witman and Sebens 1992; Rosenberg and Selander 2000), various crabs and shrimps (Wurzian 1977; Aronson 1987; Makra and Keegan 1999), the Norwegian lobster (Baden et al. 1990a) and asteroids (Sloan 1980; Gaymer et al. 2002), but have never included actinians.

During 2005 and 2006, we artificially induced smallscale oxygen deficiencies in situ in the North Adriatic to study the effects of hypoxia and anoxia on the structure and behaviour of the macrobenthic fauna. This study, involving time-lapse photography and sensor measurements, is the first to document a unique predatory interaction between sea anemones and brittle stars.

\section{Materials and methods}

The fieldwork was carried out from mid-September to midOctober 2005, and July to mid-October 2006, using SCUBA diving techniques. The study site was approximately $2 \mathrm{~km}$ off Piran (Slovenia, Northern Adriatic Sea; $45^{\circ}$ $32.69^{\prime} \mathrm{N} 13^{\circ} 34.94^{\prime} \mathrm{E}$ ) on muddy sand bottom at a depth of $24 \mathrm{~m}$. Both years of fieldwork yielded a total of 10 complete deployments. All were conducted with the Experimental Anoxia Generating Unit (EAGU), a specially designed and constructed state-of-the-art underwater benthic chamber which artificially induces oxygen deficiencies in situ (Stachowitsch et al. 2007).

\section{Experimental set-up}

The EAGU was deployed for up to 4 days at a time, in two different configurations, to autonomously generate oxygen crises and quantify benthic responses. Initially the system was positioned for $24 \mathrm{~h}$ in its "open" configuration $\left(50 \times 50 \times 50 \mathrm{~cm}^{3}\right.$ open-sided aluminium frame plus instrument lid) over a selected macrobenthic assemblage to document behaviour during normoxic conditions. Assemblages were selected based on the presence of a wide range of representative organisms. In a second step, the aluminium frame was exchanged for a plexiglass chamber ("closed" configuration), open on the bottom and top and of the same size as the frame and repositioned over the same assemblage for another $48-72 \mathrm{~h}$. Here, the behavioural patterns of the animals at decreasing oxygen concentrations were documented. The lid housed a digital underwater camera with time-lapse function and two flashes. It also accommodated two oxygen-, one hydrogen sulphide- and one temperature sensor, and the datalogger. The two oxygen 
sensors were mounted at different heights $(2$ and $20 \mathrm{~cm}$, respectively) above the sediment in order to detect potential oxygen gradients in the enclosed water body. The hydrogen sulphide sensor was fixed at $2 \mathrm{~cm}$ height, and the temperature sensor at $20 \mathrm{~cm}$ height above the sediment. The camera was adjusted to produce a series of images at 6-min intervals, whereas the sensor values were logged every minute (Stachowitsch et al. 2007).

After each deployment, as many organisms and biogenic structures as possible on or embedded in the soft bottom were collected by hand. In many deployments, however, the decomposition was advanced, and/or the animals were no longer visible because of an amorphous black organic layer (see Fig. 5D in Stachowitsch et al. 2007); smaller or more fragile organisms such as brittle stars were often missed. In the case of the sea anemones, some retracted deep into the sediment and could not be retrieved. The collected samples were carefully examined for surviving organisms in the laboratory and then were preserved in a $4 \%$ formalin: seawater solution.

Both sea anemones and brittle stars were common faunal elements enclosed by EAGU. The 10 deployments contained a total of 38 sea anemones (no individuals in deployment 9), of which we collected 29 individuals (Fig. 1a). They also contained at least 381 brittle stars (211 individuals were collected; Fig. 1b). The maximum density of the former was seven individuals $/ 0.25 \mathrm{~m}^{2}$ (surface enclosed by EAGU), the latter 65 individuals/ $0.25 \mathrm{~m}^{2}$. We measured the largest column diameter, height and wet weight of all preserved (contracted) sea anemones. We also measured the expanded tentacle crown diameters of each individual in the films. The size (disc diameter and arm-tip to arm-tip length) and wet weights of the brittle stars were measured based on 40 individuals collected in deployment no. 7, which was ended before they started to decompose. We used these values for a representative size frequency distribution. Because fewer individuals were always collected than those visible in the images, we also counted all brittle stars based on individual frames of each film. Three randomly chosen frames were evaluated in the closed configuration. At least one of the evaluated frames was from the hypoxic phase, when more individuals were typically visible on the surface of sponges and other organisms. The highest number counted was chosen. Finally, we measured the disc and overall diameters of the five predated ophiuroids based on the images.

Data analyses

Sea anemones were present in 9 out of 10 deployments conducted in 2005 and 2006. The total documentation time in these 9 deployments was 817 h $6 \mathrm{~min}$. Of a total of 8,290
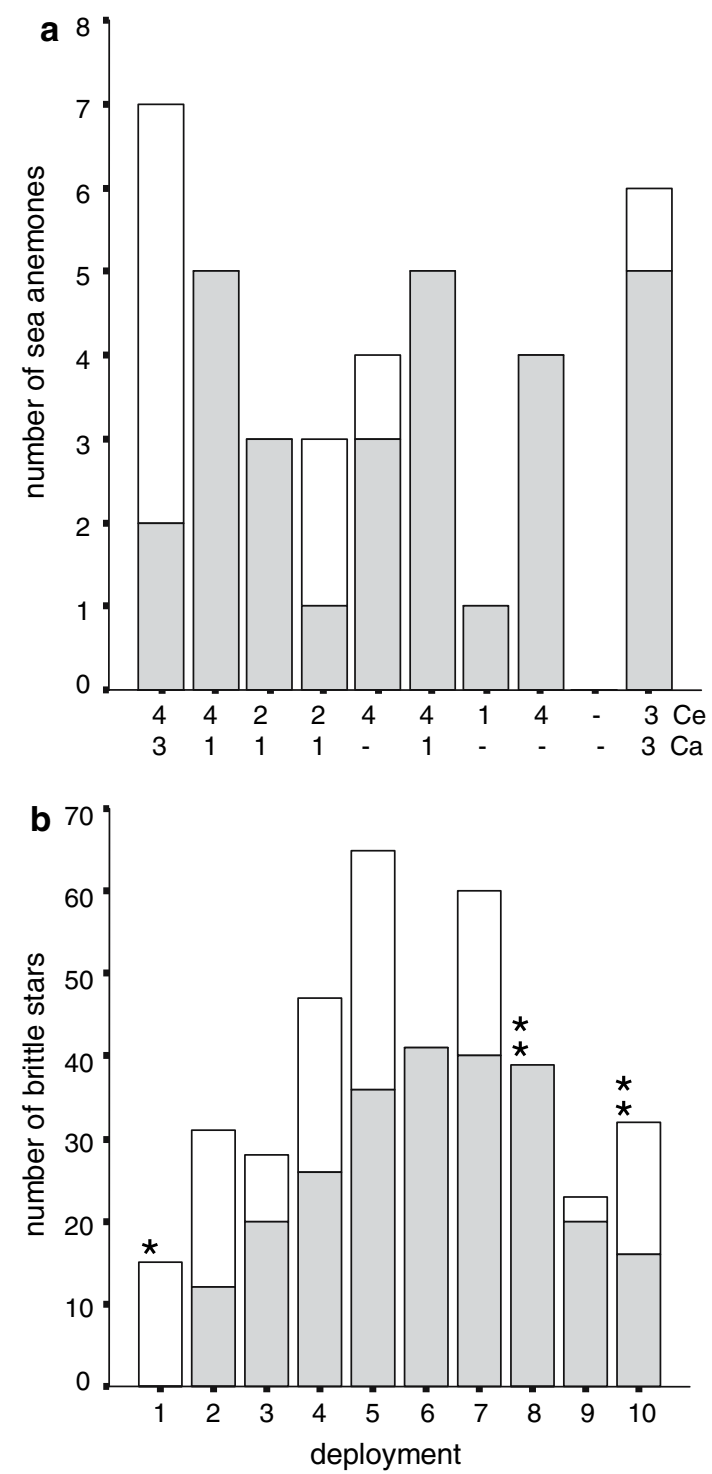

Fig. 1 Number of a sea anemones and $\mathbf{b}$ ophiuroids per deployment (area: $0.25 \mathrm{~m}^{2} ; \mathrm{Ce}=$ Cereus pedunculatus, $\mathrm{Ca}=$ Calliactis parasitica). Shaded area represents number of collected specimens, open area total number of individuals visible in film. Asterisks indicate deployments with predation events

images, 1,115 images were taken during the open, and 7,175 images during the closed EAGU configuration.

We viewed all time-lapse sequences to detect predatory events and then examined every image from the start to finish of such interactions. The predatory interactions were interpreted in the framework of the oxygen and hydrogen sulphide concentrations provided by the sensors. Dissolved oxygen (DO) concentrations during open EAGU configuration generally varied from $3.0-5.0 \mathrm{ml} \mathrm{l}^{-1}$ (with occasional peaks after storm conditions). In all deployments, the closed chamber created hypoxic conditions within $24 \mathrm{~h}$, and anoxic conditions in about 2 days. Dead organisms were not removed during the deployment; this simulated 
natural mortality events and avoided disturbing the experimental set-up. It also promoted hydrogen sulphide $\left(\mathrm{H}_{2} \mathrm{~S}\right)$ formation in the chamber within 1 day of anoxic conditions. Temperature remained steady from start to finish in the early deployments $\left(17-19^{\circ} \mathrm{C}\right)$, and thus was not measured in subsequent deployments. Time-lapse movies were produced from the still image series using the Adobe Premier 6.5 program. Statistical analyses were performed using the software package SPSS 15 .

Anemone feeding behaviour

Anemone behaviour was recorded in categories that described reactions to decreasing oxygen and increasing hydrogen sulphide concentrations. For Cereus, behavioural categories included:

- tentacle crown habitus-tentacle crown either open (all tentacles fully expanded) or closed (animal retracted so that no tentacles visible).

- Extension-tentacle crown, normally expanded on the sediment surface, is elevated to different degrees above the surface (minor: slightly above the sediment; major: far above the sediment, with part of column clearly visible).

- body contraction-column diameter of extended animals severely constricted or strongly inflated at some level above the sediment.

- body rotation-rotating or swaying movement of highly extended individual.

- mouth and pharynx protrusion-mouth "puckered" or part of pharynx protruded (after McFarlane 1975).

For Calliactis, the above categories were modified: extension was deleted and tentacle crown orientation (i.e. away from or towards the sediment), as well as detachment from the substratum (a hermit-crab-occupied snail shell in the predation event recorded here), was added.

Predation involved a clear sequence of events: feeding, digestion and regurgitation. The feeding response involved contact, pulling in of the prey, transfer to the mouth and ingestion itself. After contact was made, the captured food was held on the tentacles and moved to the mouth by ingestive movements, i.e. the tentacles shortened and bent, and the tentacle crown margin folded over toward the mouth. Feeding was completed when the last remnants of the brittle star arms were no longer visible and the anemones' mouth was closed. Digestion (McFarlane 1975) or retention (Shick 1991) comprised the time between mouth closure and the beginning of regurgitation. Regurgitation was complete when the remains of the brittle stars were ejected fully and the mouth closed again.

\section{Results}

Behaviour during normal oxygen concentrations

The percent areal coverage by individual anemone crowns as measured from the images ranged from 0.11 to $3.14 \%$ (Fig. 2a). This corresponds to an average crown diameter/ anemone of $67.0 \mathrm{~mm}$ (range: $19-100 \mathrm{~mm}$ ). The wet weights of the collected individuals ranged from $0.14 \mathrm{~g}$ in deployment 3 (one individual) to $24.73 \mathrm{~g}$ in deployment 5 (three individuals).

In all open EAGU configurations, we observed that the sea anemones Cereus pedunculatus or Calliactis parasitica contacted potential prey items such as small crabs. Anemones also contacted Ophiothrix individuals under normal
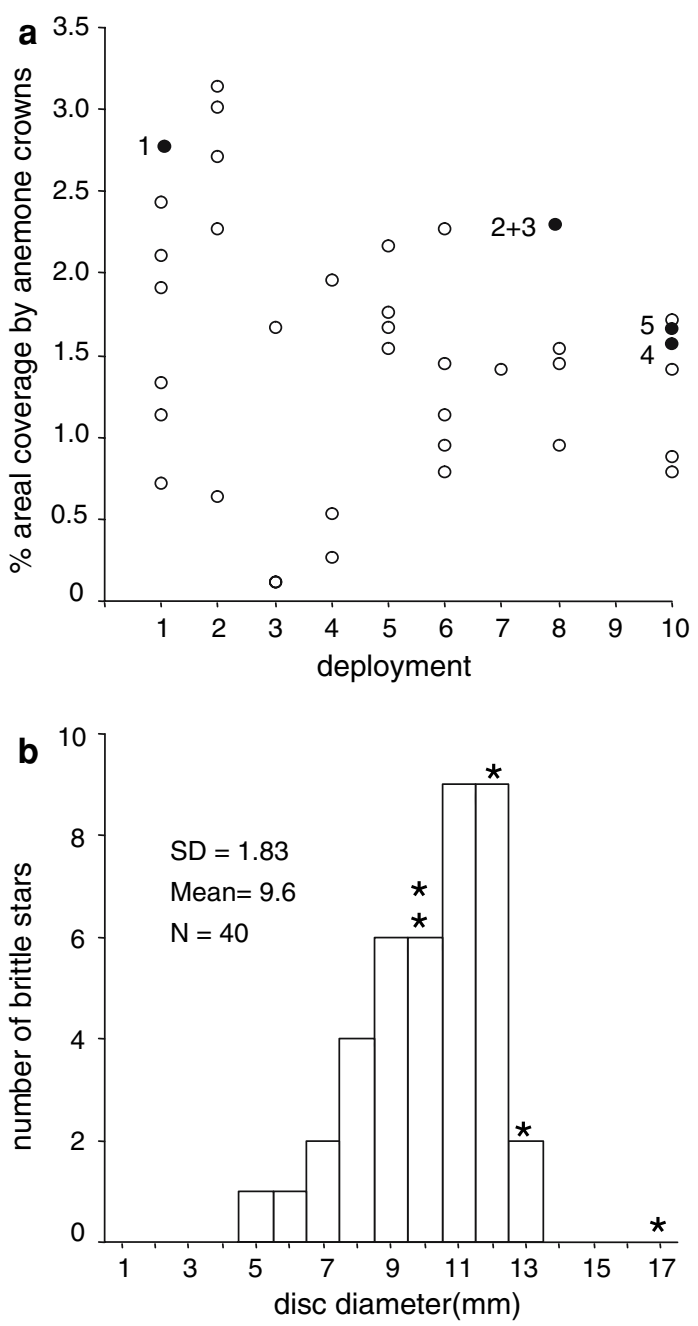

Fig. 2 a Percent areal coverage by crowns of all 38 sea anemones documented in the films (tentacle crown diameter: average $67 \mathrm{~mm}$, range: $19-100 \mathrm{~mm}$ ). Solid dots represent predatory individuals, and numbers refer to predation events listed in Table 1. b Representative size-frequency distribution of adult Ophiothrix quinquemaculata based on 40 individuals collected in deployment 7. Asterisks indicate size class of the five predatory individuals in deployments 1,8 and 10 
oxygen conditions, but this never developed into predatory interactions. When Cereus pedunculatus contacted crabs or brittle stars, the tentacle crown mostly remained open, and the touched part sometimes slightly undulated. If the anemones retracted into the sediment, this lasted for only a few minutes. Contact with large, moving organisms such as the gastropod Hexaplex trunculus or hermit crabs caused prompt retraction-sometimes completely and for several hours-into the sediment. Calliactis parasitica reacted quickly, although less sensitively, to contact with other organisms: the crown undulated or retracted slightly. Complete contraction was observed only when the hermit crab that carried the anemones forced its way between closely adjoining multi-species clumps. One scenario was visible in all images: brittle stars, clinging to sponges or ascidians, generally maintained a safety distance of at least 1.0 $2.0 \mathrm{~cm}$ from nearby anemones. If contact was made with an anemone, the ophiuroids immediately retracted their arms and typically moved a few centimetres away.

\section{Behaviour during decreasing oxygen concentrations}

Declining oxygen concentrations after the chamber was sealed elicited a clear change in the behaviour of ophiuroids towards sea anemones: contact with either anemone species no longer caused the brittle stars to flee. Some extended their arms to within millimetres of the anemones. If touched, however, the anemones never showed any feeding patterns in these situations, but kept their tentacle crowns wide opened.

As oxygen values approached near-anoxia, a total of five predatory interactions (13\% of the 38 sea anemones recorded) were observed in 3 out of 9 deployments. Four took place between Cereus pedunculatus and Ophiothrix quinquemaculata, and one between Calliactis parasitica and the brittle star (Table 1). Except during predation event 1 (deployment 1), hydrogen sulphide was absent. Predated brittle stars were significantly larger than a representative ophiuroid assemblage of one of the deployments (Fig. 2b; Mann-Whitney $U$ test, $Z=-2.132, P=0.033)$. The average individual wet weight was $1.31 \mathrm{~g}$, range $0.10-2.48 \mathrm{~g}$.

Predation events also tended to involve the largest sea anemones (Fig. 2a).

At the onset of each predation event, the anemones showed typical behavioural responses to oxygen stress, such as extension and rotation (Fig. 3a, b), swaying, or "mouth puckering". These behaviours increased significantly at near-anoxic conditions $\left(\leq 0.5 \mathrm{ml} \mathrm{l}^{-1}\right)$ in both species (Fig. 3, Table 2).

Most brittle stars initially responded to decreasing oxygen concentrations by arm-tipping (i.e. elevating their discs above the substrate and standing only on their arm-tips), but had already become motionless and either clung lethargically to the substrate or lay moribund on the sediment surface at the time of the predatory events.

All anemones that fed on brittle stars survived until the end of each deployment, whereas all the brittle stars died. In two deployments, a total of four Calliactis parasitica died, three of them in the longest one (depl. 1; $133 \mathrm{~h} 6 \mathrm{~min}$ closed configuration, retrieval delayed due to bad weather). No Cereus mortality occurred.

\section{Predation event $1-$ Cereus pedunculatus and Ophiothrix quinquemaculata}

The anemone raised its tentacle crown and began rotating in response to anoxia (Fig. 4a). It first caught one,
Table 1 Predatory interactions between the two anemone species and the brittle star Ophiothrix quinquemaculata

Predation events 2 and 3: same anemone individual. All times are based on 6-min time-lapse intervals. Top DO and

$\mathrm{H}_{2} \mathrm{~S}$-concentrations refer to values at onset of feeding, bottom concentrations to onset of regurgitation

Dash no regurgitation observed

a Initial contact to complete regurgitation

\begin{tabular}{|c|c|c|c|c|c|}
\hline \multirow[b]{2}{*}{ Predation event } & \multicolumn{4}{|c|}{ Cereus pedunculatus } & \multirow{2}{*}{$\begin{array}{l}\text { Calliactis } \\
\text { parasitica } \\
4\end{array}$} \\
\hline & 1 & 2 & 3 & 5 & \\
\hline \multirow[t]{2}{*}{ Deployment } & 1 & 8 & 8 & 10 & 10 \\
\hline & $17-23 / 09 / 05$ & $5-10 / 10 / 06$ & $5-10 / 10 / 06$ & $17-21 / 10 / 06$ & $17-21 / 10 / 06$ \\
\hline Feeding & $7 \mathrm{~h} 42 \mathrm{~min}$ & $2 \mathrm{~h} 18 \mathrm{~min}$ & $1 \mathrm{~h} 42 \mathrm{~min}$ & $1 \mathrm{~h} 42 \mathrm{~min}$ & $5 \mathrm{~h} 6 \mathrm{~min}$ \\
\hline Date & 19 Sept. & 7 Oct. & 7 Oct. & 19 Oct. & 19 Oct. \\
\hline Time & $14: 02-21: 44$ & 9:01-11:19 & $12: 01-13: 43$ & $01: 43-03: 25$ & 01:01-6:07 \\
\hline $\mathrm{DO}\left(\mathrm{ml} \mathrm{1}^{-1}\right)$ & 0 & 0 & 0 & 0.2 & 0.2 \\
\hline $\mathrm{H}_{2} \mathrm{~S}\left(\mu \mathrm{Mol} 1^{-1}\right)$ & 0.6 & 0 & 0 & 0 & 0 \\
\hline Digestion & $2 \mathrm{~h} 6 \mathrm{~min}$ & - & - & $12 \mathrm{~h} 36 \mathrm{~min}$ & $6 \mathrm{~h} 36 \mathrm{~min}$ \\
\hline Regurgitation & $60 \mathrm{~min}$ & - & - & $36 \min$ & $24 \mathrm{~min}$ \\
\hline Time (start) & 00:02 & - & - & $16: 13$ & $12: 55$ \\
\hline $\mathrm{DO}\left(\mathrm{ml} \mathrm{l}^{-1}\right)$ & 0 & - & - & 0.1 & 0.1 \\
\hline $\mathrm{H}_{2} \mathrm{~S}\left(\mu \mathrm{Mol} 1^{-1}\right)$ & 3.0 & - & - & 0 & 0 \\
\hline Total elapsed time ${ }^{a}$ & $10 \mathrm{~h} 48 \mathrm{~min}$ & - & - & $14 \mathrm{~h} 54 \mathrm{~min}$ & 12 h 24 min \\
\hline
\end{tabular}



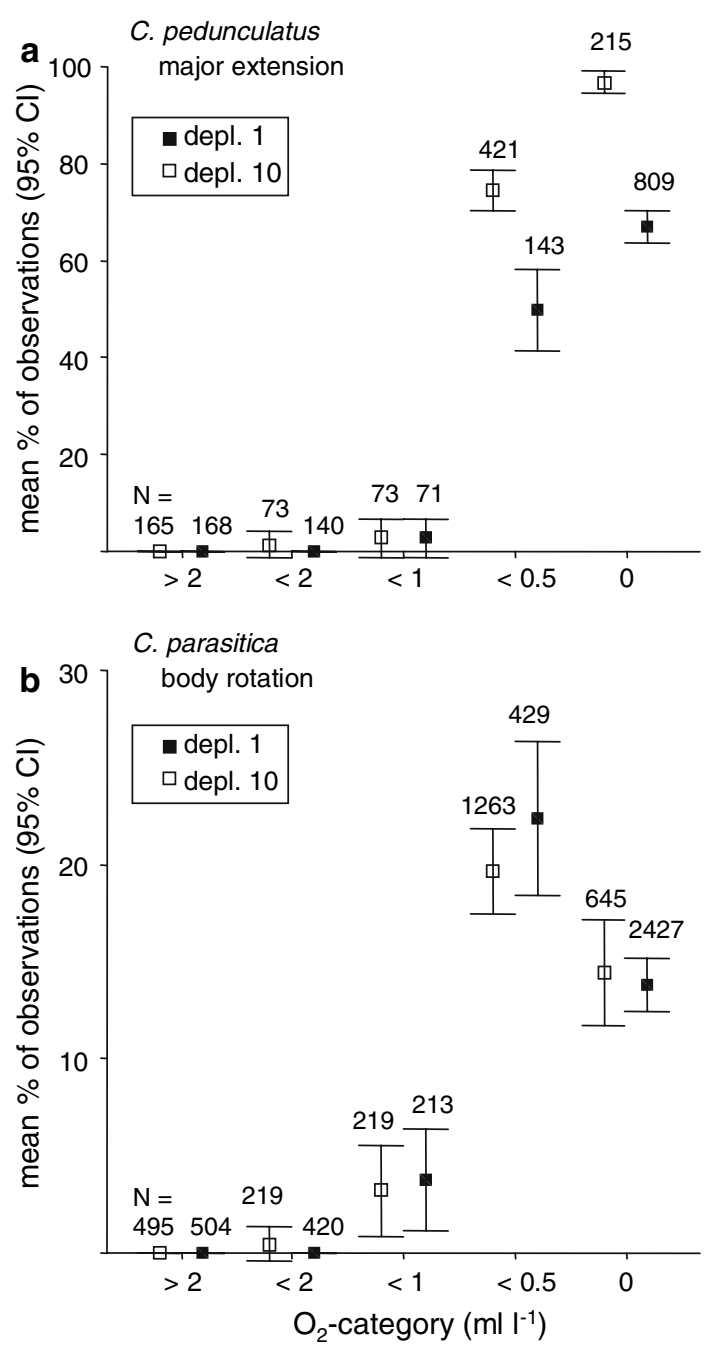

Fig. 3 Changes in sea anemone behaviour during the course of oxygen depletion in deployments 1 and 10 (the two evaluated entirely for all anemone behaviour). a Major extensions of four Cereus pedunculatus individuals from the sediment (two in each deployment). b Body rotations of six Calliactis parasitica individuals (three in each deployment). Numbers above error bars refer to number of photographs taken and evaluated per oxygen category

then a second arm of the brittle star, which resisted being pulled in by clinging to its sponge perch about $10 \mathrm{~cm}$ away (42 min; Fig. 4b). Its detachment (Fig. 4c) and transport to the mouth occurred from one image to the next (6 min; Fig. 4d, e). The complete feeding phase (7 h 42 min; Table 1) was the longest documented. This was followed $2 \mathrm{~h} 6$ min later by regurgitation of the mucusenclosed remains (Fig. 4f), which fell onto the sediment. The anemone, showing extreme pharynx protrusion, continued to move its tentacles crown until the end of the deployment 2.5 days later, despite anoxia and increasing hydrogen sulphide concentrations.
Predation events 2 and 3-Cereus pedunculatus and two Ophiothrix quinquemaculata

Both brittle stars had made contact with the anemone prior to the actual predation event: one was pulled from a sponge and remained attached to the anemone column for $90 \mathrm{~min}$ before fleeing onto its original sponge. The latter individual (event 2) was pulled from another sponge, contact was then interrupted and it remained on the sediment. Almost $2 \mathrm{~h}$ after lying motionless, it made a slight move. In the next image, the anemone swayed its column, bent its tentacle crown down and pulled in the brittle star. Body rotations and tentacle movements transported the prey towards its mouth. Feeding took more than $2 \mathrm{~h}$ (Table 1).

About 42 min after this predation event, the same anemone recaptured the other brittle star (event 3), which in the meantime had left the sponge and lay moribund on the sediment surface. Feeding ( $1 \mathrm{~h} 42 \mathrm{~min}$ ) involved the same patterns as in event 2. Moreover, the anemone briefly touched an arm of a third Ophiothrix while it devoured the second individual. The anemone moved until the end of this deployment (ca. 3 days later; $\sim 104 \mu \mathrm{Mol}^{-1} \mathrm{H}_{2} \mathrm{~S}$ ), but no regurgitation was observed.

\section{Predation event 4-Calliactis parasitica and Ophiothrix quinquemaculata}

This sea anemone was attached to a shell inhabited by the hermit crab Pagurus cuanensis, which already was overturned and largely inactive. Thus, the anemone had a considerably reduced radius of activity compared to the large areas it "sweeps" when the crab normally walks across the bottom. The brittle star lay moribund on an adjoining ascidian about $8 \mathrm{~cm}$ away. It was missing one arm, perhaps because a few images earlier it briefly ( 2 images long, i.e. $12 \mathrm{~min}$ ) touched another Calliactis specimen on the same shell.

Although initial contact was not visible, the anemone pulled the brittle star from the ascidian onto the sediment, where it landed upside-down, two arms already attached to the tentacle crown. The anemone then raised its crown and pulled the brittle star in. The ophiurid's central disc was devoured in only $12 \mathrm{~min}$; the remaining, projecting arms took another $4 \mathrm{~h} 42 \mathrm{~min}$. Mucus-covered remains (disc and attached arm stubs) were regurgitated after $6 \mathrm{~h}$. The anemone continued to move until the end of the deployment approximately 1.5 days later.

\section{Predation event 5-Cereus pedunculatus and Ophiothrix quinquemaculata}

This event was concurrent with predation event 4 . The extended anemone touched one arm of a moribund 
Table 2 Results of the MannWhitney $U$ test for differences in the number of major extensions (Fig. 3a) and body rotations (Fig. 3b) in the five oxygen categories in deployment 1 and 10
Numbers $1-5$ under

"comparison" refer to oxygencategories $>2.0-0 \mathrm{ml} \mathrm{l}^{-1} \mathrm{DO}$, respectively. Bold numbers indicate highly significant $(P<0.01)$; underlined numbers indicate significant $(P<0.05)$ differences

\begin{tabular}{|c|c|c|c|c|c|c|}
\hline & Deployment & Comparison & Mann-Whitney $U$ & Wilcoxon $W$ & $Z$ & $P$-value \\
\hline \multirow{20}{*}{$\begin{array}{l}\text { Major extension } \\
\text { (see Fig. 3a) }\end{array}$} & \multirow[t]{10}{*}{1} & 1 vs. 2 & 1176.0 & 21630.0 & 0.000 & 1.000 \\
\hline & & 1 vs. 3 & 5796.0 & 19992.0 & -2.180 & 0.029 \\
\hline & & 1 vs. 4 & 6048.0 & 20244.0 & -10.380 & $<0.001$ \\
\hline & & 1 vs. 5 & 22428.0 & 36624.0 & -15.891 & $<0.001$ \\
\hline & & 2 vs. 3 & 4830.0 & 14700.0 & -1.991 & $\underline{0.047}$ \\
\hline & & 2 vs. 4 & 5040.0 & 14910.0 & -9.616 & $<0.001$ \\
\hline & & 2 vs. 5 & 18690.0 & 28560.0 & -14.781 & $<0.001$ \\
\hline & & 3 vs. 4 & 2699.0 & 5255.0 & -6.788 & $<0.001$ \\
\hline & & 3 vs. 5 & 10287.5 & 12843.5 & -10.667 & $<0.001$ \\
\hline & & 4 vs. 5 & 47810.0 & 58106.0 & -3.991 & $<0.001$ \\
\hline & \multirow[t]{10}{*}{10} & 1 vs. 2 & 5940.0 & 19635.0 & -1.503 & 0.133 \\
\hline & & 1 vs. 3 & 5857.5 & 19552.5 & -2.131 & $\underline{0.033}$ \\
\hline & & 1 vs. 4 & 8910.0 & 22605.0 & -16.213 & $<0.001$ \\
\hline & & 1 vs. 5 & 577.5 & 14272.5 & -18.755 & $<0.001$ \\
\hline & & 2 vs. 3 & 2628.0 & 5329.0 & -0.581 & 0.561 \\
\hline & & 2 vs. 4 & 4152.5 & 6853.5 & -11.948 & $<0.001$ \\
\hline & & 2 vs. 5 & 363.0 & 3064,0 & -15.753 & $<0.001$ \\
\hline & & 3 vs. 4 & 4363.0 & 7064.0 & -11.738 & $<0.001$ \\
\hline & & 3 vs. 5 & 470.5 & 3171.5 & -15.589 & $<0.001$ \\
\hline & & 4 vs. 5 & 35121.0 & 123952.0 & -6.937 & $<0.001$ \\
\hline \multirow{20}{*}{$\begin{array}{l}\text { Body rotation } \\
\text { (see Fig. 3b) }\end{array}$} & \multirow[t]{10}{*}{1} & 1 vs. 2 & 105840.0 & 194250.0 & 0.000 & 1.000 \\
\hline & & 1 vs. 3 & 51660.0 & 178920.0 & -4.372 & $<0.001$ \\
\hline & & 1 vs. 4 & 83916.0 & 211176.0 & -11.206 & $<0.001$ \\
\hline & & 1 vs. 5 & 527184.0 & 654444.0 & -8.861 & $<0.001$ \\
\hline & & 2 vs. 3 & 43050.0 & 131460.0 & -3.994 & $<0.001$ \\
\hline & & 2 vs. 4 & 69930.0 & 158340.0 & -10.288 & $<0.001$ \\
\hline & & 2 vs. 5 & 439320.0 & 527730.0 & -8.104 & $<0.001$ \\
\hline & & 3 vs. 4 & 37180.5 & 59971.5 & -6.025 & $<0.001$ \\
\hline & & 3 vs. 5 & 232506.0 & 255297.0 & -4.181 & $<0.001$ \\
\hline & & 4 vs. 5 & 475953.0 & 3422331.0 & -4.573 & $<0.001$ \\
\hline & \multirow[t]{10}{*}{10} & 1 vs. 2 & 53955.0 & 176715.0 & -1.503 & 0.133 \\
\hline & & 1 vs. 3 & 52470.0 & 175230.0 & -3.995 & $<0.001$ \\
\hline & & 1 vs. 4 & 251212.5 & 373972.5 & -10.635 & $<0.001$ \\
\hline & & 1 vs. 5 & 136620.0 & 259380.0 & -8.812 & $<0.001$ \\
\hline & & 2 vs. 3 & 23323.5 & 47413.5 & -2.139 & $\underline{0.032}$ \\
\hline & & 2 vs. 4 & 111774.0 & 135864.0 & -7.006 & $<0.001$ \\
\hline & & 2 vs. 5 & 60766.5 & 84856.5 & -5.730 & $<0.001$ \\
\hline & & 3 vs. 4 & 115563.0 & 139653.0 & -5.948 & $<0.001$ \\
\hline & & 3 vs. 5 & 62701.5 & 86791.5 & -4.483 & $<0.001$ \\
\hline & & 4 vs. 5 & 386067.0 & 594402.0 & -2.813 & 0.005 \\
\hline
\end{tabular}

\section{Discussion and conclusions}

The sea anemones and brittle stars in our experimentally induced oxygen deficiencies repeatedly showed a series of distinctive, predictable sublethal and lethal responses that paralleled those observed in earlier benthic mortalities in the Northern Adriatic Sea (Stachowitsch 1984, 1991). All anemones responded similarly with elongation, expanded 
Fig. 4 Predation by Cereus pedunculatus on Ophiothrix quinquemaculata (predation event 1). a Overview of enclosed macroepifauna. Cereus (top arrow) with elevated tentacle crown and Ophiothrix (bottom arrow) on sponge about $10 \mathrm{~cm}$ away. b Anemone catches arm of brittle star, which holds onto sponge with one arm. c Brittle star pulled on to tentacle crown. d Anemone begins to ingest the prey. e End phase of feeding with arms still protruding from mouth. f Regurgitation of brittle star remains; note extension of anemone from sediment
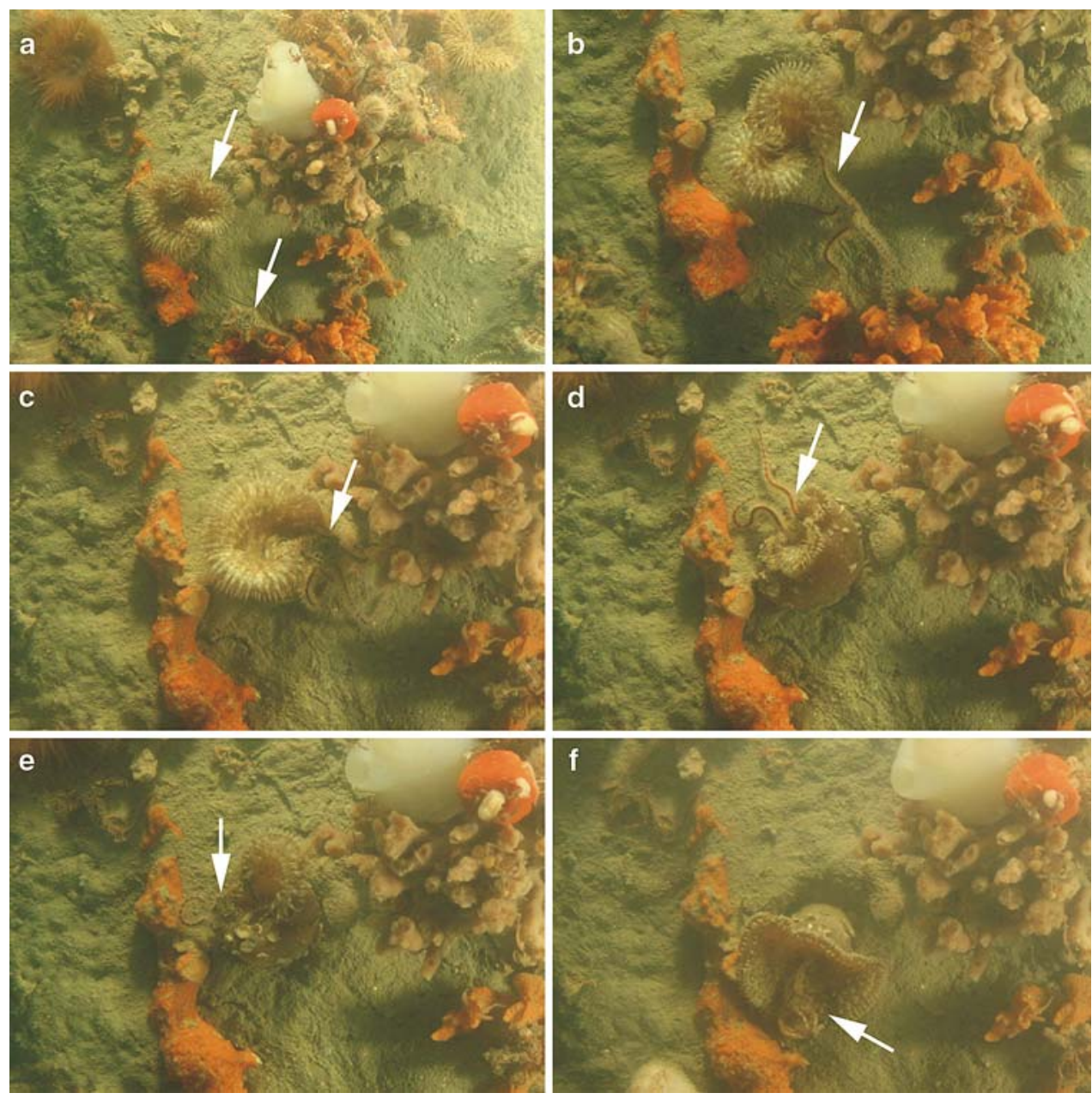

tentacle crowns, rotation, swaying and contraction. Calliactis parasitica additionally detached from their hermit-craboccupied shell. Ophiothrix quinquemaculata responded with arm-tipping and movement to higher substrates such as atop sponges and ascidians. Rising a few centimetres above the sediment surface has been observed in other studies (Baden et al. 1990b; Rosenberg et al. 1991; Sagasti et al. 2001) and is interpreted as an attempt to avoid low oxygen concentrations near the sediment surface.

With ongoing oxygen stress, however, the ophiuroids became less active and most ultimately left their perches. Most echinoderms are intolerant of low oxygen concentrations (Gray et al. 2002; Levin 2003), and our results confirm that $O$. quinquemaculata is a hypoxia-sensitive species in the Northern Adriatic Sea. All died long before the end of the deployments.

In contrast, all $C$. pedunculatus and six of ten $C$. parasitica individuals survived until the end of the deployments. This observation confirms in situ and laboratory studies that demonstrate that sea anemones are particularly tolerant to hypoxia and also can survive extended periods of anoxia (Jørgensen 1980; Wahl 1984; Stachowitsch 1991).
They can sustain their energy production when confronted with hypoxia by switching from aerobic to anaerobic pathways (e.g. opine and more efficient fermentations such as glucose-succinate or aspartate-succinate pathways; Shick 1991, p. 127). Moreover, sea anemones, like other cnidarians (scypho- and hydromedusae: Rutherford and Thuesen 2005), exhibit metabolic depression-a down regulation of metabolic demand under hypoxic conditions. Finally, behaviours such as elongation and peristalsis may increase exposure to the sea water both through the body wall and the coelenteron (Shick 1991). The lower survival rate of the epifaunal Calliactis parasitica versus the infaunal Cereus pedunculatus could reflect a potentially different anaerobic pathway or the stiffer peripheral column mesoglea of the former, which may be a stronger barrier for oxygen diffusion (Shick 1991). Note that $C$. pedunculatus is zooxanthellate (Davy et al. 1997; Visram et al. 2006) and that symbiotic anemones even inhabit depths where irradiance is greatly reduced (Muller-Parker and Davy 2001). However, the potential role of this symbiosis in the eutrophic, $24 \mathrm{~m}$ depth here remains unknown. 
While sublethal behavioural responses to declining oxygen concentrations are advantageous for surviving or avoiding hypoxic layers, they may be inappropriate for avoiding predation (Diaz and Rosenberg 1995). Large foragers can migrate into and out of hypoxic areas and thus increase their predation efficiency (Pihl et al. 1992). If, however, both predators and prey are affected, then relative tolerance will govern predation efficiency (Breitburg et al. 1994). Nestlerode and Diaz (1998) suggested that relative hypoxia tolerance might lead to selective predation on certain taxa, whereby the most intolerant prey will be exploited (Sandberg 1994).

Our results for $C$. pedunculatus and $C$. parasitica are in situ proof of this: by exploiting moribund ophiuroids, anemones switched to an alternative prey item apparently absent from their normal diet elsewhere in the Mediterranean (Greece: Chintiroglou and Koukouras 1991, 1992). This makes $O$. quinquemaculata - a highly abundant species in this community-an unexpected but potentially important secondary food source for Cereus and Calliactis during periods of oxygen stress.

Our observations suggest that the anemones were able to take advantage of stressed ophiuroids only within a narrow range of low oxygen concentrations, and that the number of contacts under all other conditions was not indicative of successful predatory interactions. In the Northern Adriatic, we never observed predatory interactions between anemones and ophiuroids during normal oxygen conditions, neither in our current EAGU experiments nor in earlier $16 \mathrm{~mm}$ time-lapse camera films (Fedra 1974). Those early films revealed that brittle stars actively and successfully avoided potential mobile predators, such as the sea star Astropecten aurantiacus and the hermit crab Paguristes eremita, fleeing before contact and maintaining a constant distance (Stachowitsch 1979). The brittle stars did not flee from all larger mobile epifauna: they climbed atop holothurians and used them as transportation. Here, we show that brittle stars, under normoxic conditions, avoided encounters with anemones as well and maintained a safe distance of at least $1-2 \mathrm{~cm}$. If they did make contact, they either retracted their arms and/or moved out of reach. If contact was made under normoxia or in the early phases of hypoxia, predation never occurred: all predation events took place during nearanoxia (Table 1).

The activity of the anemones coupled with the moribund brittle stars increased predatory feeding efficiency and reduced prey escape. In one case (event 3), a still-active brittle star initially was able to escape an anemone. In predation event 1 (Fig. 4), the anemone also required $48 \mathrm{~min}$ to pull in the living prey from its sponge perch. Moribund brittle stars, however, were pulled in without resistance: they were no longer able to use well-known post-contact avoidance strategies such as active flight or arm-autotomy (Wilkie 1978; Drolet et al. 2004).

Our results showed that the anemones which successfully consumed brittle stars were the largest within the respective deployments (Fig. 2a), and that the predated brittle stars were typically in the larger size categories (Fig. 2b). The combined reach of large, rotating anemones and the overall diameters of larger brittle stars is one explanation for this correlation. Otherwise, there was no apparent correlation between number of anemones and number of brittle stars. We attribute this in part to benthic topography. The location of the anemones on the sediment, combined with the position of the brittle stars on the multispecies clumps, will play a role in determining predation events. Nonetheless, the fact that brittle stars tended to leave aggregations during hypoxia means that the configuration and size of the multi-species clumps themselves (we tended to choose larger aggregations) are less important. Accordingly, our observations do not reflect a "worst case scenario".

Beyond mechanical stimuli, chemical stimuli are also generally required to elicit a complete feeding response in most cnidarians (Nagai and Nagai 1973; Elliott and Cook 1989; McFarlane and Lawn 1991). Chemical cues, emitted from damaged or dead individuals, can cause marine predators to act as opportunistic scavengers in lieu of their normal predatory role (Brewer and Konar 2005). Our study provides the first direct proof of this strategy in sea anemones. The combination of stimuli needed for attack, along with the normal resistance ability of the prey, could explain the relatively narrow oxygen concentration window for successful predation. Moreover, an 'aerobic shutdown' before switching to anaerobic metabolism (Shick 1991) may explain why the anemones fed on the ophiuroids only after a lengthier severe hypoxia.

The duration and extent of many behaviours are altered by stress (Abrams 1982). During hypoxia, for example, behaviour related to respiration can increase (siphon activity of bivalves; Rosenberg et al. 1991), and those not related to respiration can decrease (the duration of amphipod swimming activity; Johansson 1997). This also pertains to prey-handling times, which take longer under hypoxic conditions (shore crab Carcinus maenas; Brante and Hughes 2001). In the present study, prey handling and consumption also appeared to be prolonged by anoxia. The feeding time of the Cereus pedunculatus individual that experienced the highest $\mathrm{H}_{2} \mathrm{~S}$-concentrations and the longest anoxia (Table 1: predation event 1) was much longer than in the other individuals. The regurgitation itself also was nearly as twice as long. In contrast, the period between ingestion and regurgitation under anoxia was several times more rapid than in anemones under normoxic conditions, i.e. 1-2 days (Nagai and Nagai 1973; McFarlane 1975). 
Finally, anoxia also alters optimal foraging strategies, allowing the consumption of prey that would normally require longer handling and digestion times (Beddingfield and McClintock 1993).

In conclusion, our in situ experimental approach revealed a previously unreported predator-prey interaction. Considering the frequency of oxygen crises in the Northern Adriatic Sea, this type of predation may be a common event. Such predation reflects the different tolerances and behaviours of the species experiencing oxygen deficiency: the prey's moribund condition and the predator's tolerance favour these events. This, combined with the anemones' considerable extension and body rotation in all directions, increases their chances to contact prey. Even though the window of opportunity is relatively narrow (i.e. after brittle stars reduce their activity but before they begin to decompose), it is apparently long enough to afford the anemones an advantage in these unstable environmental conditions. This may help explain why anemones are often a dominant element in the composition of post-mass mortality benthic communities in the Northern Adriatic Sea.

Acknowledgments This research was funded by the Austrian Science Fund (FWF; project P17655-B03). We would like to thank P. Steiner, A. Haselmair and I. Gallmetzer for technical and diving support. L. Celestina refitted and maintained our boat. Special thanks to A. Malej (Director), B. Cermelj, G. Polajnar, T. Makovec and J. Forte of the Marine Biology Station (MBS) in Piran, Slovenia, for their hospitality and support during our field work. J. Ott supported this project from the very beginning. Three anonymous reviewers contributed to improving the final version of the manuscript with their detailed and constructive advice.

Open Access This article is distributed under the terms of the Creative Commons Attribution Noncommercial License which permits any noncommercial use, distribution, and reproduction in any medium, provided the original author(s) and source are credited.

\section{References}

Abrams PA (1982) Functional response of optimal foragers. Am Nat 120:382-390

Aronson RB (1987) Predation on fossil and recent ophiuroids. Paleobiology 13:187-192

Baden SP, Pihl L, Rosenberg R (1990a) Effects of oxygen depletion on the ecology, blood physiology and fishery of the Norway lobster Nephrops norvegicus. Mar Ecol Prog Ser 67:141-155

Baden SP, Loo LO, Pihl L, Rosenberg R (1990b) Effects of eutrophication on benthic communities including fish: Swedish west coast. Ambio 19:113-122

Barmawidjaja DM, van der Zwaan GJ, Jorissen FJ, Puscaric S (1995) 150 years of eutrophication in the northern Adriatic Sea: evidence from a benthic forameniferal record. Mar Geol 122:367-384

Beddingfield SD, McClintock JB (1993) Feeding behavior of the sea star Astropecten articulatus (Echinodermata: Asteroidea): an evaluation of energy-efficient foraging in a soft-bottom predator. Mar Biol 115:669-676
Brante A, Hughes RN (2001) Effect of hypoxia on the prey-handling behaviour of Carcinus maenas feeding on Mytilus edulis. Mar Ecol Prog Ser 209:301-305

Breitburg DL (1992) Episodic hypoxia in Chesapeake Bay: interacting effects of recruitment, behaviour, and physical disturbance. Ecol Monogr 62:525-546

Breitburg DL, Steinberg N, DuBeau S, Cooksey C, Houde ED (1994) Effects of low dissolved oxygen on predation on estuarine fish larvae. Mar Ecol Prog Ser 104:235-246

Brewer R, Konar B (2005) Chemosensory responses and foraging behavior of the seastar Pycnopodia helianthoides. Mar Biol 147:789-795

Buzzelli CP, Luettich RA, Powers SP, Peterson CH, McNinch JE, Pinckney JL, Paerl HW (2002) Estimating the spatial extent of bottom-water hypoxia and habitat degradation in a shallow estuary. Mar Ecol Prog Ser 230:103-112

Caruso T, Falciai L, Zupo V (2003) Decapoda Anomura Paguridea: morpho-functional relationships and influence of epibiotic anemones on shell use along a bathymetric cline. Crustaceana 76:149-165

Chintiroglou C, Koukouras A (1991) Observations on the feeding habits of Calliactis parasitica (Couch, 1842), Anthozoa, Cnidaria. Oceanol Acta 14:389-396

Chintiroglou C, Koukouras A (1992) The feeding habits of three Mediterranean sea anemone species, Anemonia viridis (Forskal), Actinia equina (Linnaeus) and Cereus pedunculatus (Pennant). Helgoländer Meeresunters 46:53-68

Danovaro R (2003) Pollution threats in the Mediterranean Sea: an overview. Chem Ecol 19:15-32

Davy SK, Lucas I, Turner JR (1997) Uptake and persistence of homologous and heterologous zooxanthellae in the temperate sea anemone Cereus pedunculatus (Pennant). Biol Bull 192:208-216

Decker MB, Breitburg DL, Purcell JE (2004) Effects of low dissolved oxygen on zooplankton predation by the ctenophore Mnemiopsis leidyi. Mar Ecol Prog Ser 280:163-167

Diaz RJ, Rosenberg R (1995) Marine benthic hypoxia: a review of its ecological effects and the behavioural responses of benthic macrofauna. Oceanogr Mar Biol Annu Rev 33:245-303

Drolet D, Himmelman JH, Rochette R (2004) Use of refuges by the ophiuroid Ophiopholis aculeata: contrasting effects of substratum complexity predation risk from two predators. Mar Ecol Prog Ser 284:173-183

Eby LA, Crowder LB, McClellan CM, Peterson CH, Powers MJ (2005) Habitat degradation from intermittent hypoxia: impacts on demersal fishes. Mar Ecol Prog Ser 291:249-261

Elliott J, Cook CB (1989) Diel variation in prey capture behavior by the corallimorpharian Discosoma sanctithomae: mechanical and chemical activation of feeding. Biol Bull 176:218-228

Fedra K (1974) Filtrierverhalten und Aktivitätsrythmik bei Ophiothrix quinquemaculata (Echinodermata). Wien: Bundestaatliche Hauptstelle für wissenschaftliche Kinematographie (Research Film B-1567)

Fedra K (1978) On the ecology of the north Adriatic Sea. Wide-range investigations on the benthos: the Gulf of Trieste. Memorie di Biogeografia Adriatica 9:69-87

Fedra K, Ölscher EM, Scherübel C, Stachowitsch M, Wurzian RS (1976) On the ecology of a North Adriatic benthic community: distribution, standing crop and composition of the macrobenthos. Mar Biol 38:129-145

Gaymer CF, Himmelman JH, Johnson LE (2002) Effect of intra- and interspecific interactions on the feeding behaviour of two subtidal sea stars. Mar Ecol Prog Ser 232:149-162

Gray JS, Wu RS, Or YY (2002) Effects of hypoxia and organic enrichment on the coastal marine environment. Mar Ecol Prog Ser 238:249-279 
Johansson B (1997) Behavioural response to gradually declining oxygen concentration by Baltic Sea macrobenthic crustaceans. Mar Biol 129:71-78

Jørgensen BB (1980) Seasonal oxygen depletion in the bottom waters of a Danish fjord and its effect on the benthic community. OIKOS 34:68-76

Justic D (1987) Long-term eutrophication of the Northern Adriatic Sea. Mar Pollut Bull 18:281-284

Levin LA (2003) Oxygen minimum zone benthos: adaptation and community response to hypoxia. Oceanogr Mar Biol Annu Rev 41:1-45

Lotze HK, Lenihan HS, Bourque BJ, Bradbury RH, Cooke RG, Kay MC, Kidwell SM, Kirby MX, Peterson CH, Jackson JBC (2006) Depletion, degradation, and recovery potential of estuaries and coastal seas. Science 312:1806-1809

Makra A, Keegan BF (1999) Arm regeneration in Acrocnida brachiata (Ophiuroidea) at Little Killary, West Coast of Ireland. Biol Environ Proc R Ir Acad 99B(2):95-102

Marchetti R, Provini A, Crosa G (1989) Nutrient load carried by the river Po into the Adriatic Sea, 1968-87. Mar Poll Bull 20:168172

McFarlane ID (1975) Control of mouth opening and pharynx protrusion during feeding in the sea anemone Calliactis parasitica. J Exp Biol 63:615-626

McFarlane ID, Lawn ID (1991) The senses of sea anemones: response of the SSI nerve net to chemical and mechanical stimuli. Hydrobiologia 216/217:599-604

Miller DC, Poucher SL, Coiro L (2002) Determination of lethal dissolved oxygen levels for selected marine and estuarine fishes, crustaceans, and a bivalve. Mar Biol 140:287-296

Mistri M (2004) Effects of hypoxia on predator-prey interactions between juvenile Carcinus aestuarii and Musculista senhousia. Mar Ecol Prog Ser 275:211-217

Montagna PA, Ritter C (2006) Direct and indirect effects of hypoxia on benthos in Corpus Christi Bay, Texas, U.S.A. J Exp Mar Biol Ecol 330:119-131

Muller-Parker G, Davy SK (2001) Temperate and tropical algal-sea anemone symbioses. Invert Biol 120:104-123

Nagai Y, Nagai S (1973) Feeding factors for the sea anemone Anthopleura midorii. Mar Biol 18:55-60

Nestlerode JA, Diaz RJ (1998) Effects of periodic environmental hypoxia on predation of a tethered polychaete, Glycera americana: implications for trophic dynamics. Mar Ecol Prog Ser 172:185-195

Pihl L, Baden SP, Diaz RJ, Schaffner LC (1992) Hypoxia-induced structural changes in the diet of bottom-feeding fish and Crustacea. Mar Biol 112:349-361

Rabalais NN, Turner RE (2001) Hypoxia in the Northern Gulf of Mexico: description, causes and change. Coast Estuar Stud 58:1-36

Rosenberg R, Selander E (2000) Alarm signal response in the brittle star Amphiura filiformis. Mar Biol 136:43-48

Rosenberg R, Hellman B, Johansson B (1991) Hypoxic tolerance of marine benthic fauna. Mar Ecol Prog Ser 79:127-131

Rutherford LD, Thuesen EV (2005) Metabolic performance and survival of medusae in estuarine hypoxia. Mar Ecol Prog Ser 294:189-200
Sagasti A, Schaffner LC, Duffy JE (2001) Effects of periodic hypoxia on mortality, feeding and predation in an estuarine epifaunal community. J Exp Mar Biol Ecol 258:257-283

Sandberg E (1994) Does short-term oxygen depletion affect predatorprey relationships in zoobenthos? Experiments with the isopod Saduria entomon. Mar Ecol Prog Ser 103:73-80

Shick JM (ed) (1991) A functional biology of sea anemones. Chapman \& Hall, New York

Sloan NA (1980) Aspects of the feeding biology of asteroids. Oceanogr Mar Biol Annu Rev 18:57-124

Stachowitsch M (1979) Movement, activity pattern, and role of a hermit crab population in a sublittoral epifaunal community. J Exp Mar Biol Ecol 39:135-150

Stachowitsch M (1980) The epibiothic and endolithic species associated with the gastropod shells inhabited by the hermit crabs Paguristes oculatus and Paguristes cuanensis. PSZNI Mar Ecol 1:73-101

Stachowitsch M (1984) Mass mortality in the Gulf of Trieste: the course of community destruction. PSZNI Mar Ecol 5:243-264

Stachowitsch M (1991) Anoxia in the Northern Adriatic Sea: Rapid death, slow recovery. Geol Soc Spec Publ 58:119-129

Stachowitsch M, Riedel B, Zuschin M (2007) Oxygen depletion and benthic mortalities: the first in situ experimental approach to documenting an elusive phenomenon. Limnol Oceanogr Methods $5: 344-352$

Stierhoff KL, Targett TE, Miller KL (2006) Ecophysiological responses of juvenile summer and winter flounder to hypoxia: experimental and modelling analyses of effects on estuarine nursery quality. Mar Ecol Prog Ser 325:255-266

Tallqvist M, Sandberg-Kilpi E, Bonsdorff E (1999) Juvenile flounder, Platichthys flesus (L.), under hypoxia: effects on tolerance, ventilation rate and predation efficiency. J Exp Mar Biol Ecol 242:75-93

UNEP United Nations Environment Programme (2004) GEO Year Book 2003. GEO Section/UNEP, Nairobi

Visram S, Wiedenmann J, Douglas AE (2006) Molecular diversity of symbiotic algae of the genus Symbiodinium (Zooxanthellae) in cnidarians of the Mediterranean Sea. J Mar Biolog Assoc UK $86: 1281-1283$

Wahl M (1984) The fluffy sea anemone Metridium senile in periodically oxygen depleted surroundings. Mar Biol 81:81-86

Wilkie IC (1978) Arm autotomy in brittle stars (Echinodermata: Ophiuroidea). J Zool 186:311-330

Witman JD, Sebens KP (1992) Regional variation in fish predation intensity: a historical perspective in the Gulf of Maine. Oecologia 90:305-315

Wu RSS (2002) Hypoxia: from molecular responses to ecosystem responses. Mar Pollut Bull 45:35-45

Wurzian RS (1977) Predator-prey interaction between the crab Pilumnus hirtellus (Leach) and the brittle star Ophiothrix quinquemaculata (D.Chiaje) on a mutual sponge substrate. In: Keegan BF, O'Ceidigh P, Boaden PJS (eds) Biology of benthic organisms. Pergamon Press, Galway, pp 613-620

Zuschin M, Pervesler P, Stachowitsch M, Kollmann H (1999) Structural features and taphonomic pathways of a high-biomass epifauna in the northern Gulf of Trieste, Adriatic Sea. Lethaia 32:299-317 